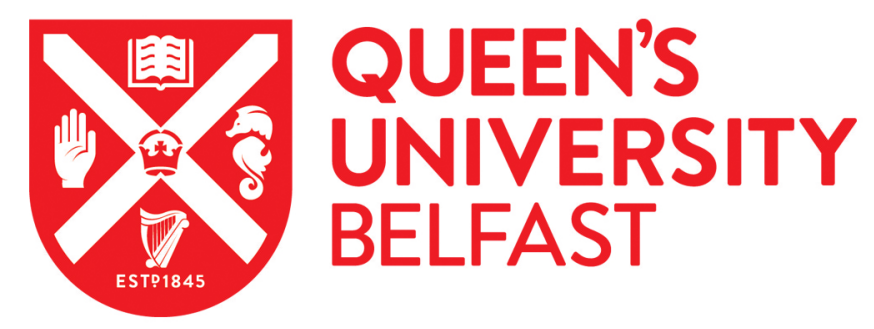

\title{
Exploring consumer purchase intentions towards traceable minced beef and beef steak using the Theory of Planned Behavior
}

Spence, M., Stancu, V., Elliott, C. T., \& Dean, M. (2018). Exploring consumer purchase intentions towards traceable minced beef and beef steak using the Theory of Planned Behavior. Food Control, 91, 138-147. https://doi.org/10.1016/j.foodcont.2018.03.035

\section{Published in:}

Food Control

\section{Document Version:}

Peer reviewed version

Queen's University Belfast - Research Portal:

Link to publication record in Queen's University Belfast Research Portal

\section{Publisher rights}

(c) 2018 Elsevier.

This manuscript is distributed under a Creative Commons Attribution-NonCommercial-NoDerivs License

(https://creativecommons.org/licenses/by-nc-nd/4.0/), which permits distribution and reproduction for non-commercial purposes, provided the author and source are cited.

\section{General rights}

Copyright for the publications made accessible via the Queen's University Belfast Research Portal is retained by the author(s) and / or other copyright owners and it is a condition of accessing these publications that users recognise and abide by the legal requirements associated with these rights.

Take down policy

The Research Portal is Queen's institutional repository that provides access to Queen's research output. Every effort has been made to ensure that content in the Research Portal does not infringe any person's rights, or applicable UK laws. If you discover content in the Research Portal that you believe breaches copyright or violates any law, please contact openaccess@qub.ac.uk. 


\section{Accepted Manuscript}

Exploring consumer purchase intentions towards traceable minced beef and beef steak using the Theory of Planned Behavior

Michelle Spence, Violeta Stancu, Christopher T. Elliott, Moira Dean

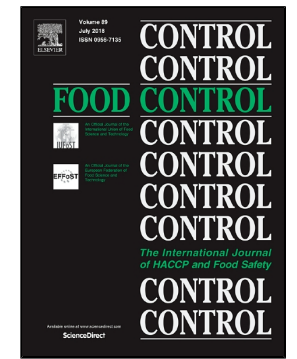
PII:
S0956-7135(18)30142-7
DOI:
10.1016/j.foodcont.2018.03.035

Reference:

JFCO 6049

To appear in:

Food Control

Received Date:

05 December 2017

Revised Date:

22 March 2018

Accepted Date:

23 March 2018

Please cite this article as: Michelle Spence, Violeta Stancu, Christopher T. Elliott, Moira Dean, Exploring consumer purchase intentions towards traceable minced beef and beef steak using the Theory of Planned Behavior, Food Control (2018), doi: 10.1016/j.foodcont.2018.03.035

This is a PDF file of an unedited manuscript that has been accepted for publication. As a service to our customers we are providing this early version of the manuscript. The manuscript will undergo copyediting, typesetting, and review of the resulting proof before it is published in its final form. Please note that during the production process errors may be discovered which could affect the content, and all legal disclaimers that apply to the journal pertain. 


\section{Exploring consumer purchase intentions towards traceable minced beef and beef steak using the Theory of Planned Behavior}

Michelle Spence ${ }^{a}$, Violeta Stancu ${ }^{b}$, Christopher T. Elliott ${ }^{\text {, }}$, Moira Dean ${ }^{a, *}$

${ }^{a}$ Institute for Global Food Security, School of Biological Sciences, Queen's University Belfast, Stranmillis Road, Belfast BT9 5AG, Northern Ireland, UK.

b MAPP Centre, Aarhus BSS, Aarhus University, Fuglesangs Allé 4, 8210 Aarhus V, Denmark.

Email addresses:

MS: m.s.spence@qub.ac.uk

VS: viost@mgmt.au.dk

CTE: chris.elliott@qub.ac.uk

MD: moira.dean@qub.ac.uk

*Corresponding author: Prof Moira Dean, Institute for Global Food Security, School of Biological Sciences, Queen's University Belfast, Stranmillis Road, Belfast BT9 5AG, Northern Ireland, UK. Phone: +44(0)28 9097 6561; e-mail: moira.dean@qub.ac.uk 


\section{Abstract}

2 Recently, traceability labels with a quick response $(\mathrm{QR})$ code have been printed on product packaging to help consumers easily access traceability information through their smart phones. We analyzed consumer $(n=616)$ attitudes and purchase intentions towards traceable minced beef/beef steak in England, and identified psychosocial determinants of their purchase using the theory of planned behavior (TPB). Respondents held a general favorable attitude with positive behavioral beliefs and high trust towards the traceable product. In the TPB model, attitude was the main determinant of intention to purchase each traceable product, followed by subjective norm and perceived behavioral control (PBC). The predictive power of the TPB model increased marginally for each sub-group when it was extended with habits, trust, and frequency of purchase. In the TPBextended minced beef model, $\mathrm{PBC}$ was no longer a significant driver, and trust replaced subjective norm as the second most important predictor. In the TPB-extended beef steak model, attitude, subjective norm and PBC were all still significant drivers of intention, however, in order of importance, production process habits and origin habits were more important than $\mathrm{PBC}$. These findings have importance for those involved in the production and marketing of beef.

Keywords: Food traceability; Theory of planned behavior; Minced beef; Beef steak; Trust; Habits. 
As a result of the globalization of the food supply chain, it has become increasingly difficult to ensure the safety, quality and integrity of the food we eat. A number of food crises, such as the occurrence of Bovine Spongiform Encephalopathy (BSE or mad cow disease) in cattle, dioxin in chicken feed and horsemeat in beef products have threatened consumer confidence in the food industry and provided the impetus for the progression of laws, policies and standards regarding food safety and quality management (Hobbs, 2004). In Europe, the BSE crisis in the early- and midenabled buyers to know where beef on sale originated) (EU, 2000) and to the introduction of a mandatory "one step back"-“one step forward” traceability system in 2005 under General Food Law Regulation (EC) No. 178/2002) (EU, 2002), which was made specific to food of animal origin from 2012 by Regulation (EC) No. 931/2011 (EU, 2011). Traces of undeclared horsemeat discovered in products sold or labelled as beef in 2013 have also compelled food business operators to consider how they can go beyond mandatory traceability requirements and develop systems which integrate information at all stages of the supply chain. This has been encouraged by technological innovations in relation to product traceability (reviewed by (Bosona \& Gebresenbet, 2013)), for example, DNA/RFID traceability solutions incorporating block chain technology (Tian, 2016) are being applied in the UK pork industry (Cranswick, 2017). This type of control system could, once fully implemented, provide both the opportunity for knowledge transfer within the supply chain and an assurance of authenticity, due to the clear proof of provenance. Indeed, Mai and colleagues (Mai, Bogason, Arason, Arnason \& Matthiasson, 2010) offer empirical evidence that implementing RFIDbased traceability can bring quantifiable benefits at different steps in the supply chain.

Bosona and Gebresenbet (2013, p. 35) proposed a new comprehensive description of food traceability in 2013, redefining it as "a part of logistics management that captures, stores and transmits adequate information about a food, feed, food-producing animals or substances at all stages in the food supply chain so that the product can be checked for safety and quality control, traced 
upward, and tracked downward at any time". Essentially there are three primary benefits of a traceability system in the agricultural and food supply chain (Aung \& Chang, 2014): (1) improved food supply chain management (e.g., improved inventory management), (2) improved food crisis management (e.g., reduced recall expenses), and (3) increased marketability of foods with verifiable quality attributes which are unique or undetectable. Indeed, consumer demand for credence quality attributes (e.g., organic production and fair trade) is encouraging firms to invest in traceability as a means of product differentiation (Boecker, Hobbs, Kerr, \& Yeung, 2013). Recently, QR (quick response) codes have been printed on meat packaging (Huang, 2017) to offer consumers easy access to meat traceability information through their smart phones.

Consumer research on food traceability has primarily focused on exploring consumer preferences and willingness-to-pay (WTP) for labelling programs associated with the quality assurance attributes of meat traceability systems (see for example, Cicia \& Colantuoni, 2010; Dickinson \& Von Bailey, 2005; Hobbs, Bailey, Dickinson, \& Haghiri, 2005; Lim, Hu, Maynard, \& Goddard, 2014), and to a lesser extent, on consumers' general perceptions of food traceability systems (Van Rijswijk \& Frewer, 2012; Van Rijswijk, Frewer, Menozzi, \& Faioli, 2008; Wu, Xu \& Gao, 2011) and traceable food (Chen \& Huang, 2013; Menozzi, Halawany-Darson, Mora, \& Giraud, 2015; Song, Wang, \& $\mathrm{Hu}, 2017)$. While some early research indicated that consumers had little interest and understanding of food traceability (Gellynck \& Verbeke, 2001; Giraud \& Amblard, 2003), collectively, the body of literature suggests that safety and quality are linked to traceability in the mind of the consumer (Giraud \& Halawany, 2006; Van Rijswijk \& Frewer, 2008; Van Rijswijk et al., 2008), and that traceability may contribute to improving consumer confidence in the food system, especially if it is used as a vehicle to deliver credible quality assurances (Hobbs et al., 2005; Verbeke \& Ward, 2006). Under the latter condition, traceability-related assurances about on-farm production methods, origin, authenticity, and food safety tend to elicit a positive price premium across a number of countries (Hobbs, 2016). 
Although research has investigated consumers' perceptions of food traceability, relatively little is

known about consumers' purchase intentions toward traceable food or the main psychosocial antecedents of these intentions (Menozzi et al., 2015). Therefore, the aim of this present study was to explore consumer attitudes and purchase intentions towards traceable beef in England, and identify psychosocial determinants of its purchase. Beef was selected as it has been the subject of a number of high profile 'food scares' regarding its safety, quality and integrity, and consumers perceive that traceability is of primary importance for this category of foods (Van Rijswijk \& Frewer, 2012). Specifically, two beef products were chosen - minced beef and whole muscle beef steak - as these products tend to differ significantly in price and an unpublished focus group study $(\mathrm{n}=69$ participants) conducted by the authors (Spence et al., Unpublished results), showed that UK consumers viewed that minced beef was 'more easy to be made inauthentic' than whole muscle cuts like beef steak. Given this, there may be differences in purchasing determinants between products. As previously mentioned, traceability solutions incorporating block chain technology (Tian, 2016) are currently being applied in the UK food industry (Cranswick, 2017). For this reason, we obtained data from respondents living in England (the largest country in the UK).

We used the theory of planned behavior (TPB) (see Ajzen, 1991) as our conceptual framework, which has proved to be successful in predicting and explaining human behavior in the area of health and food choice (Dean, Raats, \& Shepherd, 2008). The TPB postulates that attitudes (positive or negative evaluations of the behavior), subjective norms (the influence of the thoughts and attitudes of others towards the behavior), and perceived behavioral control (PBC; the extent to which an individual feels able to perform a behavior) lead to the formation of a behavioral intention, which is a precursor of behavior. Therefore, consistent with the theory, we suggest that the more favorable the attitude and subjective norm, and the greater the $\mathrm{PBC}$, the stronger the intention to purchase traceable minced beef/beef steak.

In addition to the original constructs above, other constructs, such as past behavioral frequency, habit strength and trust have been added to the TPB with both theoretical and empirical justifications 
(Menozzi et al., 2015). Work undertaken with the addition of these variables has been shown to

increase the predictive power of the model in particularly relevant areas such as intention to purchase traceable chicken and honey (Menozzi et al., 2015).

The present study attempts to first test the TPB model by measuring attitudes to traceable minced beef/beef steak (vs. conventional beef), perceived social pressure pressure towards buying traceable minced beef/beef steak (subjective norms), and perceived ability to find and understand additional information about the origin and production process of traceable minced beef/beef steak (PBC) and how they influence purchase intentions. Second, it tests an extended version of the TPB model including habits, trust and frequency of minced beef/beef steak purchase which may explain more of the variance in intention to purchase traceable minced beef/beef steak. Such research contributes to the explanation of food-related behaviors, i.e., intention to purchase traceable food, by providing evidence for the role of psychosocial variables.

\section{Material and Methods}

\subsection{Data collection and sample description}

A survey involving 616 respondents (male and female, aged 18-65 years) from the North and South of England was conducted via in-home face-to-face Computer Assisted Personal Interviewing (CAPI) in August 2016. To ensure sufficient variance in both the dependent and independent variables under study, participants were selected using quota sampling to ensure that (a) each respondent had some responsibility for buying minced beef/beef steak for their household; (b) at least $40 \%$ of the respondents used food labels 'almost every time' (4) as a minimum on a scale of 1 ('never') to 5 ('every time') when buying a product for the first time and choosing between two or more food products; and (c) there was roughly the same percentage of respondents from higher- and lower-social class households. Approximately half of the respondents answered questions related to traceable minced beef $(n=313)$, and the other half $(n=303)$ answered questions related to traceable beef steak. On average, interviews lasted 25 minutes. The data were collected by a professional interviewer from a marketing research agency who explained to respondents that there were "no right 
or wrong answers' and that their answers would be treated confidentially. The study was approved by the Queen's University Belfast Ethical Committee and verbal consent was obtained from each respondent. Demographic details and characteristics of the respondents are detailed in Table 1. 47\% of respondents stated that they used food labels 'almost every time/every time' when buying a product for the first time, while $46 \%$ stated that they used food labels 'almost every time/every time' when choosing between two or more products. Seventy-nine percent of respondents were smartphone users and 37\% had previously used their smartphone to scan a QR code. When respondents were asked how much they trusted different individuals/organizations to provide them with accurate information about food and drink on a 7-point Likert-type scale ( 1 = "strongly distrust", $7=$ "strongly trust"), they gave the highest trust ratings to an independent government body responsible for food safety and hygiene (i.e., Food Standards Agency) (5.6 \pm 1.5$)$, followed by consumer organizations (e.g., Which?, the largest independent consumer body in the UK) (5.5 \pm 1.5$)$, university research scientists $(5.2 \pm 1.5)$, environmental organizations $(5.1 \pm 1.4)$, food and drink supermarkets (4.7 \pm 1.4$)$, industry scientists (4.6 \pm 1.5$)$, food and drink manufacturers $(4.6 \pm 1.4)$, and the media $(3.1 \pm 1.5)$.

\subsection{Questionnaire design and outline}

The questionnaire items were defined, drawing on guidelines for constructing a TPB based questionnaire (Ajzen, 1991; Ajzen, 2006) and previous research on similar topics (Menozzi et al., 2015; Van Rijswijk \& Frewer, 2008; Van Rijswijk et al., 2008), including an unpublished focus group study ( $\mathrm{n}=69$ participants) conducted by the authors (Spence et al., Unpublished results), exploring consumer perceptions and attitudes towards food authenticity and traceability in beef products. The questionnaire contained closed-ended questions, and was initially piloted among 20 individuals for understanding and technical functioning (question order, response categories, filters, interviewer instructions, overall duration). At the outset, we obtained a measure of minced beef/beef steak purchasing frequency (past behavior) and habits. Following this, participants were then provided with a definition and example of traceable minced beef/beef steak (described below) before 
completing items measuring behavioral beliefs, attitudes, subjective norms, PBC and intention.

157 Finally, trust, WTP, and socio-demographics (education, age, social class, gender, number of 158 children and adults in household) were recorded.

\subsection{Definition and pictorial example of traceable minced beef/beef steak}

The interviewer read the following definition of traceable minced beef/beef steak to the respondent: "traceable minced beef/beef steak is different to other minced beef/beef steak widely available in stores because it has unique details by which you can trace it back to the specific farm or farms on which it was raised. As a consumer, you can check the whole life story of traceable minced beef/beef steak, from the farm on which it was bred - to the retailer, by entering a code online or by scanning a QR code on the pack via your smart phone. You can obtain information about its farmer, the production process of the beef steak/minced beef (e.g., feed, rearing conditions, transport, slaughter and processing), country and region of origin, and an assurance from an independent body that this information can be trusted". A visual aid showing a traceable minced beef/beef steak product was then shown to the respondent (Figure 1) to illustrate the concept.

\subsection{Measures}

Items (listed in Table 2$)$ were scored on a 7-point Likert-type scale $(1=$ "strongly disagree", 7 = "strongly agree", unless otherwise indicated).

Habits: The four-item self-behavioral automaticity index (Gardner, Abraham, Lally, \& de Bruijn, 2012): (“[Behavior X is something...]" "I do automatically", "I do without having to consciously remember", "I do without thinking", "I start doing before I realize I'm doing it") was used to measure three types of habits (looking for information about the country or region of origin, looking for information about the production process, and looking for information about food assurance schemes).

Behavioral beliefs: To measure behavioral beliefs, participants responded to nine statements that compared traceable minced beef/beef steak to that currently available in stores (e.g., traceable minced beef/beef steak will more likely/likely be: healthier, tastier, more expensive, of known origin, 
safer, of more satisfying quality, authentic, more environmentally friendly, have higher animal welfare standards).

Attitude: Attitude towards purchasing traceable minced beef/beef steak in comparison to that currently available in stores was measured by four semantic differential scales: two which tapped the affective (bad-good, displeased-pleased) aspect of attitude and two which tapped the cognitive

187 (foolish-wise, harmful-beneficial) aspect of attitude.

Subjective norm: The perceived social pressure towards buying traceable minced beef/beef steak was assessed as five social norms among family and friends, university scientists, the media, the food industry, and other important people.

Perceived behavioral control: Respondent's perception of their ability to find and understand additional information about the origin and production process of traceable minced beef/beef steak was assessed by six items.

Purchase intention: Intention to purchase traceable minced beef/beef steak was assessed by three items: "when traceable minced beef/beef steak becomes available I intend to buy it", "when traceable minced beef/beef steak becomes available I will look for it", and "when traceable minced beef/beef steak becomes available it will be important to me to buy it".

Trust: Trust in the traceability system was evaluated with three items: "I trust that traceable minced beef/beef steak can be traced back to the actual farm", "I trust the information provided about the production process and origin of the traceable minced beef/beef steak" and "I trust that traceable minced beef/beef steak is authentic which means it has not been tampered with in any way and it is what it says it is".

$W T P$ : Respondents indicated how much more (as a percentage of the conventional products price) they would pay for traceable minced beef/beef steak in response to the following item: "suppose the price of minced beef/beef steak currently available in the supermarket is $£ 4.00$ for a $500 \mathrm{~g}$ pack/£8.67 for two steaks. The price of the traced minced beef/beef steak with the unique identity details and the additional available information will be higher but it is not determined yet. How much more would 
you be willing to pay to purchase $500 \mathrm{~g}$ of traceable minced beef/two traceable beef steaks?

Participants chose between the following options: $0 \%, 5 \%, 10 \%, 15 \%, 20 \%, 30 \% 40 \%, 50 \%, 60 \%$, $70 \%, 80 \%, 90 \%$ and $100 \%$. The price of the conventional minced beef/beef steak was based upon the market price of the respective product sold in June 2016 by one leading UK supermarket.

\subsection{Data analysis}

All analyses were conducted using IBM SPSS Statistics for Windows version 21.0 (IBM

214 Corporation, Armonk, NY, USA), with a p-value $p<0.05$ considered to be significant.

Descriptive and factor analysis: A descriptive sub-group (mean and SD) and sub-group analysis

(independent-samples $t$-tests for continuous variables and chi-square tests for categorical variables)

was first performed on the questionnaire items. Likert-type scale data for each of the 42 items (Table

2) was then entered into a maximum likelihood factor analysis with Direct Oblimin rotation. A nine-

factor solution was selected on the basis that this was in line with the theoretical expectations and conceptualizations of the target constructs. Each variable loaded cleanly onto one factor above the recommended level of 0.4 (Table 3). Internal reliabilities of all constructs (Table 3 ) were higher that the recommended level of 0.70 (Eiser \& Morse, 2001). The items within each construct were averaged, thus the scores ranged from 1 to a maximum of 7 , with higher values indicating stronger (i.e., more positive) levels of the construct. Pearson correlations measured the strength of the relationship between constructs within the models, behavioral beliefs and attitude, and behavioral beliefs and intention.

Regression analysis: Initially, a hierarchical multiple regression examined the association between TPB model constructs (attitude, subjective norm and PBC) and intention to purchase each traceable product. Then, we tested an extended version of the TPB model including habits, trust, and frequency of minced beef or beef steak purchase ( 0 less than four times per month/1 once or more weekly) as predictors of the intention to purchase traceable minced beef/beef steak. In all regressions, statistics were above 0.2). 


\section{Results}

\subsection{Descriptive summary}

Participants in each sub-group reported a general favorable attitude with positive behavioral beliefs and high trust towards the traceable product (Table 2). Participants viewed that buying traceable minced beef/beef steak, in comparison to the conventional product, would be wise/beneficial and make them feel good/pleased. Specifically, participants thought that the traceable product would more likely be of a known origin, authentic, safer and have higher welfare standards (all items scored above 5 in both sub-groups). Participants also thought that traceable minced beef/beef steak would be more expensive but have almost the same taste as the conventional product. With regard to the high score for the trust construct, participants trusted the traceability information, authenticity, and production procedures associated with minced beef/beef steak. At the same time, differences were found in these three constructs (attitude, behavioral beliefs, and trust) between subgroups: those who answered questions on traceable beef steak (vs. minced beef) expressed a significantly more favorable attitude in three out of four items (good/pleased/wise), and significantly more favorable behavioral beliefs in five out of nine items (healthier, tastier, safer, of more satisfying quality, more environmentally friendly). Concurrently, those who answered questions on traceable beef steak (vs. minced beef), expressed significantly greater levels of trust that the product was authentic and could be traced back to the actual farm. The mean scores for these three constructs (attitude, behavioral beliefs, and trust) were significantly different between sub-groups.

With regard to the high score for the PBC construct, participants in each sub-group perceived that they had a similar ability to find and understand additional information about the production process and origin of traceable minced beef/beef steak. A slightly positive score was also registered on mean intention for the traceable minced beef and beef steak sub-group ( 4.56 and 4.78, respectively, $p=$ 0.28); among participants, $61 \%$ of the minced beef sub-group and $66 \%$ of the beef steak sub-group agreed that they intended to purchase the traceable product once it becomes available, while others were either neutral (11\% and 12\% for the minced beef and beef steak sub-group, respectively) or in disagreement ( $28 \%$ and $22 \%$, for the minced beef and beef steak sub-group, respectively). 
Participants in each sub-group also reported similar low levels of subjective norms, production process habits, and food assurance scheme habits (i.e., the sample means for each construct were slightly below the mid-point, 4), and country or region of origin habits that centered around the mid264 point willing to pay a $5-30 \%$ premium. In the minced beef sub-group, $29 \%$ of the sample indicated that they would be unwilling to pay any price premium, while $57 \%$ would be willing to pay a $5-30 \%$ 271 premium.

\subsection{Predicting intentions}

Correlations between the TPB and the TPB-extended constructs for each sub-group are shown in

Table 4. All constructs, with the exception of frequency of purchase, correlated significantly with intention to purchase traceable minced beef/beef steak. Attitude had the strongest relationship with intention, indicating that those with a more positive attitude towards the traceable product in each sub-group were more likely to intend to purchase it. There were also moderate positive correlations between intentions and each of the following constructs: subjective norm (both sub-groups), PBC (both sub-groups), trust (both sub-groups), country of origin habits (both sub-groups) and food assurance habits (minced beef sub-group only).

The TPB model explained (based on $\mathrm{R}^{2}$ adj) $57 \%$ of the variance in intention to purchase traceable minced beef and $51 \%$ of the variance in intention to purchase traceable beef steak (Table 5). Attitude was the main determinant of intention to purchase the traceable product in each sub-group, followed by subjective norm, and PBC. Therefore, having a more favorable attitude towards the traceable product $(\beta=0.60$ and $\beta=0.49$ for the minced beef and beef steak sub-group, respectively), a higher level of subjective norm supportive of its purchase $(\beta=0.20$ and $\beta=0.26$ for the minced beef and 
287 beef steak sub-group, respectively), and a higher PBC regarding finding and understanding its

traceability information $(\beta=0.11$ and $\beta=0.16$ for the minced beef and beef steak sub-group,

respectively) were associated with a greater intention to purchase it.

The explained variance (based on $\mathrm{R}^{2}{ }_{\text {adj }}$ ) in intention to purchase traceable beef increased

marginally to $62 \%$ for the minced beef sub-group $(p<0.001)$ and $53 \%$ for the beef steak sub-group

$(p=0.008)$ when the TPB model was extended with country of origin habits, production process

habits, food assurance habits, trust and frequency of purchase. Attitude $(\beta=0.48)$ and subjective

norm $(\beta=0.20)$ were both still significant drivers of intention to purchase traceable minced beef,

however, trust $(\beta=0.22)$ was a greater significant predictor of intention than subjective norm, and

PBC was no longer a predictor. Country of origin habits and food assurance habits did not emerge as

significant predictors ( $p=0.06$ and $p=0.05$, respectively) within the traceable minced beef model.

In comparison, attitude $(\beta=0.41)$, subjective norm $(\beta=0.27)$ and $\operatorname{PBC}(\beta=0.12)$ were all still

significant drivers of intention to purchase traceable beef steak, however, production process habits

$(\beta=0.16)$ and origin habits $(\beta=0.13)$ were greater significant predictors of intention than $\mathrm{PBC}$, and

trust did not emerge as a significant predictor $(\beta=0.12, p=0.06)$.

\subsection{Explaining intentions}

To gain further understanding of the reasons influencing the intention to purchase traceable minced beef/beef steak, the behavioral beliefs were correlated with attitude and intention. Table 6 shows that all behavioral beliefs correlated significantly $(p<0.001)$ with attitude within each sub-group.

Additionally, all behavioral beliefs, with the exception of 'traceable beef steak will likely be more expensive', correlated significantly $(p<0.001)$ with intention within each sub-group.

\section{Discussion}

Food traceability systems aim to improve food supply chain management, especially in relation to the control of a food crisis, and enable producers to deliver verifiable product information regarding credence quality attributes (e.g., organic production and fair trade). The objectives of this survey study were to explore consumer attitudes and purchase intentions towards traceable minced beef and 
313 beef steak in England, and to identify psychosocial determinants of their purchase intentions using 314 both the TPB model and the TPB- extended model.

315 Our study has shown that the most positive item connected with traceable minced beef and beef steak is the belief that it will more likely be of a known origin, followed closely by trust that the traceable product can be traced back to the actual farm. The crucial role of origin in the consumer decision making process has been demonstrated in previous studies. For example, Menozzi et al. (2015) showed that knowing the origin of chicken was the item with the highest connection to traceable chicken in both France and Italy. As shown by DEFRA (Department for Environment, Food \& Rural Affairs, 2015), the value that UK consumers place on country of origin labelling appears to have increased as a result of the horsemeat adulteration scandal in 2013, indicating that origin, for many consumers, might be a cue for authenticity. Indeed, in the present study, the third most positive belief connected with traceable beef in each sub-group is the belief that it will more likely be authentic. Similarly, Van Rijswikk et al. 2008, who investigated consumer perceptions of traceability by means-end-chain laddering in four European countries, found that origin was an important attribute for a consumer that was linked to products being controlled/“"guaranteed", which in turn was linked to both trust/confidence and food quality and that food quality was linked with food safety and finally health.

Given UK focus group discussions (Spence et al., Unpublished results) revealed that consumers view conventional minced beef as being 'more easy to be made inauthentic' than beef steak, we had anticipated that traceable minced beef would score more favorably than traceable beef steak in comparison to the conventional product with regard to single attitude and belief items. However, those who answered questions on traceable beef steak expressed a significantly more favorable score in three out of four attitude items and five out of nine belief items. While we are unsure of the reasons for this finding we would suggest that it merits further investigation. Differences in product trust where, however, as expected; those who answered questions on traceable beef steak expressed 
whole-muscle cut derived from one source, providing easier traceability. Despite these differences between sub-groups, intention to buy traceable mince was the same as intention to buy traceable beef steak, however, traceable beef steak (vs. traceable minced beef) obtained a significantly lower price premium. This is may be because beef steak has a higher base price than minced steak.

The predictive power of the TPB model increased marginally from 57 to $62 \%(p<0.001)$ for the traceable minced beef sub-group and from $51 \%$ to $53 \%(p=0.008)$ for the traceable beef steak subgroup when the model was extended with country of origin habits, production process habits, food assurance habits, trust, and frequency of purchase constructs. These results on the TPB model compare favorably with findings from a meta-analysis (Armitage \& Conner, 2001) looking at data from 258 different studies which showed that the TPB accounted for 39\% of the variance in intention. Comparing the $\mathrm{R}^{2}$ adj statistics from the TPB and TPB-extended models, the addition of the five extra constructs added 5\% explained variance to the TPB minced meat model and only $2 \%$ explained variance to the TPB beef steak model. While the former finding is consistent with a previous study (Menozzi et al., 2015) which demonstrated a 5\% boost in explained variance for traceable chicken in France (from $60 \%$ to $65 \%$, using TPB and TPB-extended models, respectively), our findings indicate that the extended models were, in this study and especially for beef steak, less parsimonious to a model comprised solely of TPB constructs. These preliminary findings, however, should be replicated before a definitive conclusion is reached as to the potential role of these additional constructs in the TPB model of purchase intentions towards traceable food.

In the TPB model, attitude was the main determinant of intention to purchase each traceable product, followed by subjective norm and PBC which contributed comparatively less. In the extended TPB model for the minced beef sub-group, PBC was no longer a significant driver, and trust replaced subjective norm as the second most important predictor. In the extended TPB model for the beef steak sub-group, attitude, subjective norm and PBC were all still significant drivers of intention, however, in order of importance, production process habits and origin habits were more important than PBC. In line with findings reported in Menozzi’s study (2015), which showed that 
attitudes (assessed by seven belief items) drive the intention to purchase traceable chicken in France, it would therefore seem reasonable that those wishing to promote traceable beef purchase in England should start designing interventions (e.g., public information campaigns) which enable consumers to not only recognize, but appreciate the increased value of traceable beef. The present study shows that, with the exception of the belief that the traceable product will likely be more expensive, all behavioral beliefs should be incorporated into any campaigns. For those wishing to market traceable minced beef, beliefs about its quality, authenticity, safety, tastefulness and healthfulness appear to be most important, whereas quality, healthfulness and environmental friendliness are most important for beef steak. This, however, is only a starting point for influencing intentions (and consequently behavior) as many other factors need also to be considered.

Although meta-analysis (Armitage \& Conner, 2001) has shown that the subjective norm is a weak predictor of intentions, this study, similar to Menozzi et al. (2015), demonstrated that subjective norm is an important positive antecedent of purchase intention. Specifically, the opinion of family, university scientists, the media, the food industry/supermarkets and other people important to the respondents had a significant effect on intention to buy traceable beef. Therefore, marketing campaigns may also need to be targeted specifically to these people of influence. Interestingly, when the TPB model was extended, trust became significant in the minced beef sub-group and replaced subjective norm as the second most important predictor. The finding that participants' intention to purchase traceable minced beef is driven by trust in the effectiveness of the traceability system (i.e., the belief that beef can be traced back to the actual farm, and information about it can be trusted to be genuine) is in line with other studies who have explored this construct on consumer outcomes within the context of the TPB ( Lobb, Mazzocchi, \& Traill, 2007; Menozzi et al., 2015). For example, Menozzi et al. (2015) showed that trust in the effectiveness of the traceability system was the main determinant of traceable chicken/honey purchase in Italy. Similarly, Stefani, Cavicchi, Romano \& Lobb (2008) found that trust in food-chain actors (from farmers through retailers) reduces the level of perceived risk and plays an indirect role in explaining intention to purchase. Thus, in addition to 
improving attitudes towards traceable beef, we must also try to build and maintain trust in the

traceability system itself. In relation to this, it is worth considering the sources (Mazzocchi, Lobb,

Bruce Traill, \& Cavicchi, 2008) that might play a key role in the system and in the communication of

messages related to it. For instance, we found that respondents placed most trust in an independent government body responsible for food safety and hygiene (i.e., Food Standards Agency) to provide them with accurate information about food and drink, suggesting that the involvement of this body in the traceability system would likely increase trust in the effectiveness of the traceability system. The fact that trust in the traceability system was only a significant predictor of intention in the minced beef sub-group and not in the beef steak sub-group is noteworthy - perhaps this finding is due to the fact that conventional minced beef is 'more easy to be made inauthentic' than whole muscle cuts like beef steak (Spence et al., Unpublished results).

Whilst habit has been found to be a predictor of consumer outcomes within the context of the TPB (de Bruijn, 2010; Menozzi et al., 2015; Norman \& Conner, 2006), this study has demonstrated that production process habits (i.e., looking for information about the production process) and origin habits (i.e., looking for information about the country or region of origin) only positively predict intention to buy traceable beef steak. Perhaps this finding reflects the fact that beef steak is a highend beef product (in comparison to minced beef) with a higher base price.

With respect to the findings discussed above, it is important that the limitations of the study are considered. Specifically, face-to-face CAPI is open to social desirability bias and techniques such as computer-assisted self-interviewing (CASI) may obtain different answers. Furthermore, behavioral intention rather than actual behavior is reported here and while intentional behavior may account for considerable variance in actual behavior (Ajzen, 1991), follow-up studies may investigate actual instore purchase of traceable beef products. As traceability perception is country- and product-specific

414 (Menozzi et al., 2015), future studies may also wish to explore purchasing intentions in different countries and towards different beef products. Indeed, with regard to product type and akin to the products affected by the horsemeat scandal, it would be interesting to see if these results would be 
replicable with beef products which are more highly processed i.e., ready meals containing processed meat. Finally, as there has been little consideration given (e.g., Chrysochou, Chryssochoidid \& Olga, 2009) to how consumers perceive and accept technologies that provide traceability information, future research in this area could provide a better understanding of the potential success of the QR code to convey traceability information to the final consumer.

\section{Conclusion}

$$
\text { Respondents held a general favorable attitude with positive behavioral beliefs and high trust }
$$
towards traceable beef. In the TPB model, attitude was the main determinant of intention to purchase each traceable product, followed by subjective norm and PBC. The predictive power of the TPB model for the minced beef and beef steak sub-group increased marginally by $5 \%$ and $2 \%$ (respectively) when the model was extended with habits, trust, and frequency of purchase. In the extended TPB model for the minced beef sub-group, PBC was no longer a significant driver, and trust replaced subjective norm as the second most important predictor. In the extended TPB model for the beef steak sub-group, attitude, subjective norm and PBC were all still significant drivers of intention, however, in order of importance, production process habits and origin habits were more important than PBC. These findings have importance for beef producers, beef labelling, and those involved in the marketing and sales of beef products.

\section{Acknowledgement}

This work was co-funded by the Economic and Social Research Council and The Food Standards

Agency [grant number ES/M003094/1]. All authors participated in the design of the study. VS and MS carried out the statistical analyses and MS and MD drafted the manuscript. All authors contributed to the manuscript by modifying, commenting and reviewing the text, and approving the final manuscript submitted for publication. The information contained in this paper reflects the authors' views; the Economic and Social Research Council and The Food Standards Agency are not liable for any information contained therein. The authors gratefully acknowledge Dr Elaine Cowan for data preparation assistance. Declarations of interest: none. 


\section{References}

444 Ajzen, I. (1991). The theory of planned behavior. Organizational Behavior and Human Decision 445

Ajzen, I. (2006). Constructing a TpB questionnaire: Conceptual and methodological considerations. Retrieved from https://people.umass.edu/aizen/pdf/tpb.measurement.pdf.

$$
\text { Processes, 50, 179-211. }
$$

Armitage, C. J., \& Conner, M. (2001). Efficacy of the theory of planned behaviour: A meta-analytic review. British Journal of Social Psychology, 40, 471-499.

Aung, M. M., \& Chang, Y. S. (2014). Traceability in a food supply chain: Safety and quality perspectives. Food Control, 39, 172-184.

Boecker, A., Hobbs, J. E., Kerr, W. A., \& Yeung, M. T. (2013). Traceability; regulatory requirements and consumer acceptance. Canadian Food Insights, 1, 35-37.

Bosona, T., \& Gebresenbet, G. (2013). Food traceability as an integral part of logistics management in food and agricultural supply chain. Food Control, 33, 32-48.

Chen, M., \& Huang, C. (2013). The impacts of the food traceability system and consumer involvement on consumers' purchase intentions toward fast foods. Food Control, 33, 313-319.

Cicia, G., \& Colantuoni, F. (2010). Willingness to pay for traceable meat attributes: A meta-analysis. International Journal on Food System Dynamics, 1, 252-263.

Chrysochou, P., Chryssochoidis, G., \& Kehagia, O. (2009). Traceability information carriers. The technology backgrounds and consumers' perceptions of the technological solutions. Appetite, $53,322-331$ 
Cranswick. (2017). Cranswick lead EU-china collaboration to tackle food fraud. Retrieved from https://Cranswick.plc.uk/news/cranswick-lead-eu-china-collaboration-tackle-food-fraud. Accessed 4 December 2017.

de Bruijn, G. (2010). Understanding college students' fruit consumption. Integrating habit strength in the theory of planned behaviour. Appetite, 54, 16-22.

Dean, M., Raats, M. M., \& Shepherd, R. (2008). Moral concerns and consumer choice of fresh and processed organic foods. Journal of Applied Social Psychology, 38, 2088-2107.

Department for Environment, Food \& Rural Affairs. (2015). Consumer preferences regarding country of origin labelling of meat. Retrieved from https://www.oecd.org/site/agrfcn/DEFRAConsumer-preferences-regarding-country $\% 20 \mathrm{of} \% 20$ origin-labelling-of-meat.pdf.

Dickinson, D. L., \& Von Bailey, D. (2005). Experimental evidence on willingness to pay for red meat traceability in the United States, Canada, the United Kingdom, and Japan. Journal of Agricultural and Applied Economics, 37, 537-548.

Eiser, C., \& Morse, R. (2001). Quality-of-life measures in chronic diseases of childhood. Health Technology Assessment (Winchester, England), 5(4), 1-157.

EU. (2000). Regulation (EC) no. 1760/2000 of the European parliament and of the council of 17 July 2000 establishing a system for the identification and registration of bovine animals and regarding the labelling of beef and beef products and repealing Council Regulation (EC) No 820/97. Retrieved from https://www.fsai.ie/uploadedFiles/Legislation/Food_Legisation_Links/Meat__Fresh_Meat/ConsolReg1760_2000.pdf

EU. (2002). Regulation (EC) no. 178/2002 of the European parliament and of the council of 28 January 2002 laying down the general principles and requirements of food law, establishing the 
European food safety authority and laying down procedures in matters of food safety. Retrieved from ood_Law/Reg178_2002.pdf.

EU. (2011). Regulation (EC) no. 931/2011 of 19 September 2011 on the traceability requirements set by regulation (EC) no 178/2002 of the European parliament and of the council for food of animal origin. Retrieved from https://www.fsai.ie/uploadedFiles/Legislation/Food_Legisation_Links/General_Principles_of_F ood_Law/Reg931_2011.pdf.

Gardner, B., Abraham, C., Lally, P., \& de Bruijn, G. J. (2012). Towards parsimony in habit measurement: Testing the convergent and predictive validity of an automaticity subscale of the self-report habit index. The International Journal of Behavioral Nutrition and Physical Activity, 9, 102.

Gellynck, X., \& Verbeke, W. (2001). Consumer perception of traceability in the meat chain. Agrarwirtschaft, 50, 368-374.

Giraud, G., \& Amblard, C. (2003). What does traceability mean for beef meat consumer? Food Science, 23, 40-64.

Giraud, G., \& Halawany, R. (2006). Consumers' perception of food traceability in Europe. In International food and agribusiness management association symposium. June 10-11, 2006. Buenos Aires (Argentina). Retrieved from https://ideas.repec.org/p/ags/eaae98/10047.html.

Hobbs, J. E. (2004). Information asymmetry and the role of traceability systems. Agribusiness, 20, 397-415. 
Hobbs, J. E. (2016). Effective use of meat traceability in food supply chains. In M. Espineira, \& F. Santaclara J (Eds.), Advances in food traceability techniques and technologies; improving quality throughout the food chain (pp. 321-336). Duxford, UK: Woodhead Publishing.

Hobbs, J. E., Bailey, D., Dickinson, D. L., \& Haghiri, M. (2005). Traceability in the Canadian red meat sector: Do consumers care? Canadian Journal of Agricultural Economics, 53, 47-65.

Huang, E. (2017). Blockchain could fix a key problem in China's food industry: The fear of food made in china. Retrieved from https://qz.com/1031861/blockchain-could-fix-a-key-problem-inchinas-food-industry-the-fear-of-food-made-in-china/. Accessed 4 December 2017.

Lim, K. H., Hu, W., Maynard, L. J., \& Goddard, E. (2014). A taste for safer beef? How much does consumers' perceived risk influence willingness to pay for Country-of-Origin labeled beef. Agribusiness, 30, 17-30.

Lobb, A. E., Mazzocchi, M., \& Traill, W. B. (2007). Modelling risk perception and trust in food safety information within the theory of planned behaviour. Food Quality and Preference, 18, 384-395.

Mai, N., Gretar Bogason, S., Arason, S., Víkingur Árnason, S., \& Geir Matthíasson, T. (2010). Benefits of traceability in fish supply chains-case studies. British Food Journal, 112, 976-1002.

Mazzocchi, M., Lobb, A., Bruce Traill, W., \& Cavicchi, A. (2008). Food scares and trust: A European study. Journal of Agricultural Economics, 59, 2-24.

Menozzi, D., Halawany-Darson, R., Mora, C., \& Giraud, G. (2015). Motives towards traceable food choice: A comparison between French and Italian consumers. Food Control, 49, 40-48. 
528 Norman, P., \& Conner, M. (2006). The theory of planned behaviour and binge drinking: Assessing 529 the moderating role of past behaviour within the theory of planned behaviour. British Journal of 530 Health Psychology, 11, 55-70.

Song, H., Wang, R., \& Hu, Y. (2017). Consumers' purchase intentions toward traceable BeefEvidence from Beijing, China. American Journal of Industrial and Business Management, 7, 1128-1135.

Stefani, G., Cavicchi, A., Romano, D., \& Lobb, A. E. (2008). Determinants of intention to purchase chicken in Italy: The role of consumer risk perception and trust in different information sources. Agribusiness, 24, 523-537.

Tian, F. (2016). An agri-food supply chain traceability system for China based on RFID \& blockchain technology. Paper presented at the 13th International Conference on Service Systems and Service Management (ICSSSM), 1-6.

Van Rijswijk, W., \& Frewer, L. J. (2008). Consumer perceptions of food quality and safety and their relation to traceability. British Food Journal, 110, 1034-1046.

Van Rijswijk, W., \& Frewer, L. J. (2012). Consumer needs and requirements for food and ingredient traceability information. International Journal of Consumer Studies, 36, 282-290.

Van Rijswijk, W., Frewer, L. J., Menozzi, D., \& Faioli, G. (2008). Consumer perceptions of traceability: A cross-national comparison of the associated benefits. Food Quality and Preference, 19, 452-464.

Verbeke, W., \& Ward, R. W. (2006). Consumer interest in information cues denoting quality, traceability and origin: An application of ordered probit models to beef labels. Food Quality and Preference, 17, 453-467. 
$550 \mathrm{Wu}, \mathrm{L} ., \mathrm{Xu}, \mathrm{L} ., \quad \&$ Gao, J. (2011). The acceptability of certified traceable food among Chinese

$551 \quad$ consumers. British Food Journal, 113, 519-534.

552

553

554

555

556

557

558

559

560

561

562

563

564

565

566

567 
Table 1

Demographic details and characteristics of the total study sample and according to whether they completed questions relating to traceable minced beef or beef steak.

\begin{tabular}{|c|c|c|c|c|}
\hline & & $\begin{array}{c}\text { Total } \\
\mathrm{n}=616 \\
\%\end{array}$ & $\begin{array}{c}\text { Minced beef } \\
\mathrm{n}=313 \\
\%\end{array}$ & $\begin{array}{c}\text { Beef steak } \\
\mathrm{n}=303 \\
\%\end{array}$ \\
\hline \multirow[t]{2}{*}{ Gender } & Male & 42 & 44 & 40 \\
\hline & Female & 58 & 56 & 60 \\
\hline \multirow[t]{3}{*}{ Age } & $18-29$ yrs & 22 & 23 & 21 \\
\hline & $30-49 \mathrm{yrs}$ & 42 & 42 & 43 \\
\hline & $50-64$ yrs & 36 & 36 & 37 \\
\hline \multirow[t]{2}{*}{ Social class* } & $\mathrm{ABC}_{1}^{\mathrm{a}}$ & 51 & 55 & 47 \\
\hline & $\mathrm{C}_{2} \mathrm{DE}^{\mathrm{b}}$ & 49 & 45 & 53 \\
\hline \multirow[t]{3}{*}{ Highest education level } & No qualifications or compulsory level & 27 & 28 & 26 \\
\hline & $\begin{array}{l}\text { Secondary/further education (e.g., } \\
\text { NVQ) }\end{array}$ & 39 & 37 & 42 \\
\hline & University level & 34 & 36 & 32 \\
\hline \multirow[t]{6}{*}{ Occupation status } & Employed full-time (>30h per week) & 49 & 51 & 48 \\
\hline & Employed part-time ( $\leq 29 \mathrm{~h}$ per week) & 20 & 18 & 21 \\
\hline & Full-time homemaker & 5 & 5 & 5 \\
\hline & Unemployed & 12 & 10 & 13 \\
\hline & Student & 4 & 5 & 2 \\
\hline & Retired & 11 & 11 & 11 \\
\hline \multirow[t]{5}{*}{ Household size } & 1 & 13 & 12 & 15 \\
\hline & 2 & 36 & 36 & 36 \\
\hline & 3 & 17 & 16 & 19 \\
\hline & 4 & 21 & 25 & 16 \\
\hline & $5+$ & 13 & 11 & 15 \\
\hline Number of children & 0 & 60 & 60 & 59 \\
\hline \multirow[t]{3}{*}{ under 16 in household } & 1 & 16 & 17 & 16 \\
\hline & 2 & 17 & 16 & 17 \\
\hline & $3+$ & 7 & 7 & 8 \\
\hline \multirow{9}{*}{$\begin{array}{l}\text { Frequency of minced beef or beef } \\
\text { steak purchase for household }\end{array}$} & Everyday or almost everyday & 0.3 & 1 & 1 \\
\hline & Several times a week & 10 & 8 & 5 \\
\hline & Once a week & 36 & 39 & 33 \\
\hline & Several times a month & 21 & 23 & 21 \\
\hline & Once a month & 18 & 16 & 23 \\
\hline & Every two months & 8 & 5 & 5 \\
\hline & Every three/four months & 3 & 4 & 2 \\
\hline & Twice per year & 4 & 4 & 3 \\
\hline & Once per year & 1 & 1 & 2 \\
\hline \multirow{2}{*}{$\begin{array}{l}\text { Changed beef shopping behavior } \\
\text { immediately after the } 2013 \\
\text { horsemeat adulteration scandal* }\end{array}$} & No & 79 & 82 & 76 \\
\hline & Yes & 21 & 18 & 24 \\
\hline
\end{tabular}

${ }^{\text {a }}$ High social class; includes professional, managerial, technical, and skilled non-manual occupations in addition to 572 farmers with $50+$ acres.

573 b Low social class; includes skilled manual, partly skilled and unskilled occupations in addition to farmers with less than 57450 acres.

$575 *$ There was a significant association between sub-group (i.e., those who completed questions on traceable minced beef 576 vs. those who completed questions on traceable beef steak) and (a) whether social class was high or low $\chi^{2}(1)=4.36, p$ $<0.05$ and (b) whether or not participants had changed their beef shopping behavior immediately after the 2013 


\section{1}

Fig. 1. Respondents were shown a visual aid, specific to minced beef or beef steak, depicting the type of traceability information which could be retrieved upon scanning the package QR code. 
Table 2

630 Mean (SD) of questionnaire items which were scored on a 7-point Likert-type scale ( 1 = "strongly disagree", $7=$ "strongly agree", unless otherwise indicated) for each sub-group (minced beef and beef steak).

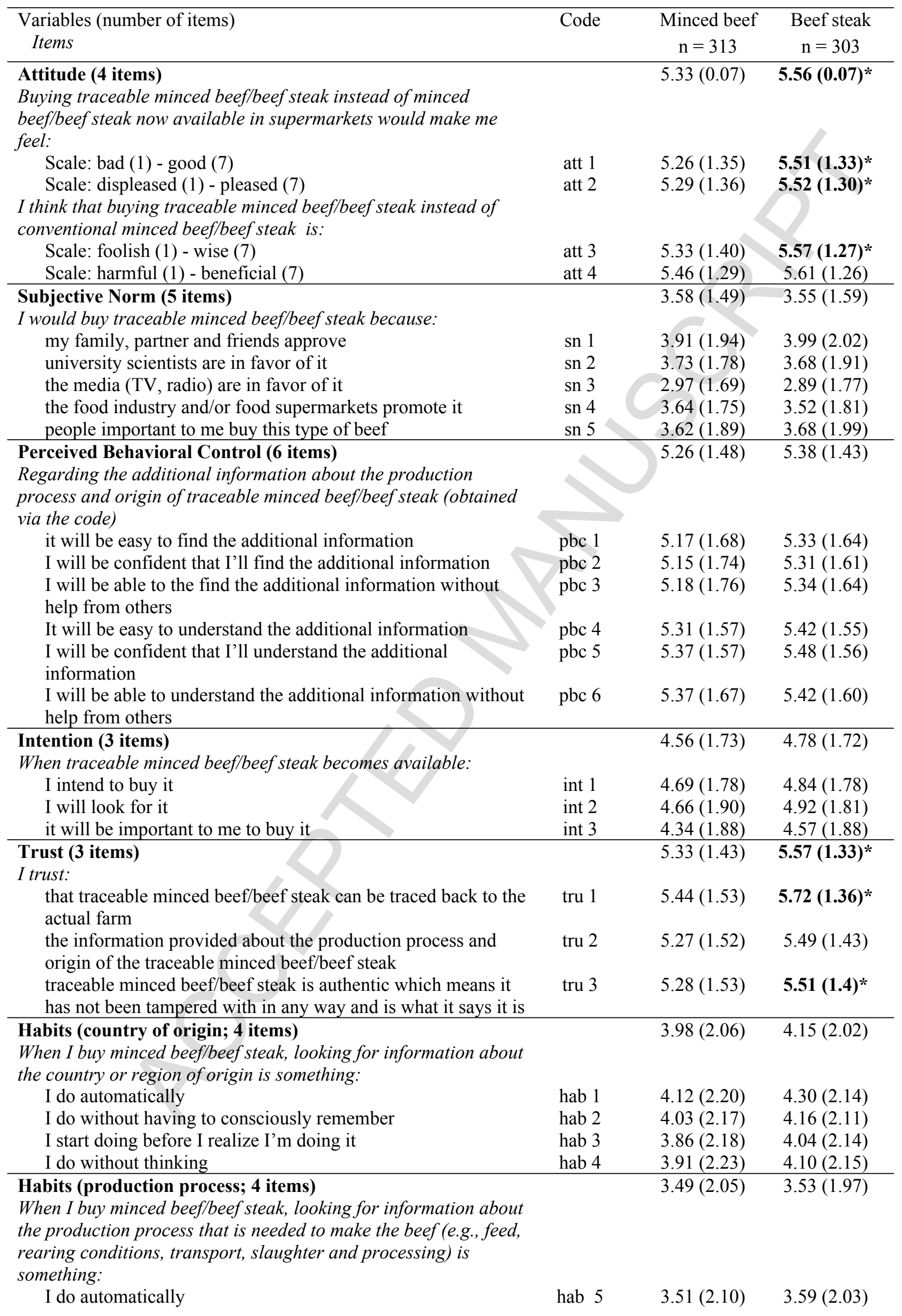


I do without having to consciously remember I start doing before I realize I'm doing it I do without thinking

\section{Habits (food assurance; 4 items)}

When I buy minced beef/beef steak, looking for food assurance schemes such as red tractor, or smaller 'niche' schemes that aim to meet particular consumer demands such as higher welfare, environmental or organic standards, is something:

I do automatically

I something I do without having to consciously remember is something I start doing before I realize I'm doing it is something I do without thinking

\section{Behavioral beliefs ( 9 items)}

Regarding traceable minced beef/beef steak, in comparison to conventional beef now available in supermarkets:

Traceable minced beef/beef steak will likely be healthier

Traceable minced beef/beef steak will likely be tastier

Traceable minced beef/beef steak will likely be more expensive

Traceable minced beef/beef steak will more likely be of known origin

Traceable minced beef/beef steak will likely be safer Traceable minced beef/beef steak will likely be of more satisfying quality

Traceable minced beef/beef steak will more likely be authentic which means it has not been tampered with in any way and it is what it says it is

Traceable minced beef/beef steak will likely be more environmentally friendly

Traceable minced beef/beef steak will likely have higher animal welfare standards

\begin{tabular}{lll} 
hab 6 & $3.51(2.12)$ & $3.55(2.05)$ \\
hab 7 & $3.45(2.10)$ & $3.50(2.06)$ \\
hab 8 & $3.48(2.17)$ & $3.50(2.05)$ \\
\hline & $3.67(1.97)$ & $3.68(1.94)$
\end{tabular}

$\begin{array}{ccc}\text { hab } 9 & 3.72(2.06) & 3.77(2.02) \\ \text { hab 10 } & 3.69(2.03) & 3.66(1.99) \\ \text { hab 11 } & 3.65(2.04) & 3.68(2.00) \\ \text { hab 12 } & 3.61(2.08) & 3.62(2.02) \\ & 4.97(1.2) & \mathbf{5 . 1 9}(\mathbf{1 . 1 4}) *\end{array}$

bel 1

bel 2

$4.58(1.77) \quad 4.95(1.73) * *$

$4.18(1.72) \quad \mathbf{4 . 5 0}(\mathbf{1 . 7 1}) *$

bel $3 \quad 5.38(1.34) \quad 5.27(1.44)$

bel 4

$5.83(1.39) \quad 5.88(1.30)$

bel 5

$5.19(1.64) \quad \mathbf{5 . 4 9}(\mathbf{1 . 4 6}) *$

bel 6

$4.71(1.74) \quad 4.97(1.56) *$

bel 7

$5.24(1.63) \quad 5.47(1.38)$

bel $8 \quad 4.61(1.71) \quad \mathbf{4 . 9 8}(\mathbf{1 . 5 3}) *$

bel $9 \quad 5.04(1.65) \quad 5.24(1.52)$

Significantly different from those who completed questions on traceable minced beef $\left(p<0.05^{*} ;<0.01^{* *}\right.$; bold numbers highlights significance).

8


Table 3

651 Standardized factor loadings and Cronbach's alpha.

\begin{tabular}{|c|c|c|c|c|}
\hline \multirow[t]{2}{*}{ Code } & \multicolumn{2}{|c|}{ Minced meat } & \multicolumn{2}{|c|}{ Beef steak } \\
\hline & Alpha & $\begin{array}{l}\text { Factor } \\
\text { loadings }\end{array}$ & Alpha & $\begin{array}{l}\text { Factor } \\
\text { loadings }\end{array}$ \\
\hline \multirow{5}{*}{$\begin{array}{l}\text { Attitude } \\
\text { att } 1 \\
\text { att } 2 \\
\text { att } 3 \\
\text { att } 4\end{array}$} & 0.93 & & 0.94 & \\
\hline & & 0.83 & & 0.85 \\
\hline & & 0.89 & & 0.93 \\
\hline & & 0.74 & & 0.79 \\
\hline & & 0.58 & & 0.67 \\
\hline \multirow{6}{*}{$\begin{array}{l}\text { Subjective Norm } \\
\text { sn } 1 \\
\text { sn } 2\end{array}$} & 0.88 & & 0.89 & \\
\hline & & 0.57 & & 0.71 \\
\hline & & 0.72 & & 0.82 \\
\hline & & 0.85 & & 0.78 \\
\hline & & 0.84 & & 0.71 \\
\hline & & 0.67 & & 0.78 \\
\hline \multirow{7}{*}{$\begin{array}{l}\text { Perceived Behavioral Control } \\
\text { pbc } 1 \\
\text { pbc } 2 \\
\text { pbc } 3 \\
\text { pbc } 4 \\
\text { pbc } 5 \\
\text { pbc } 6\end{array}$} & 0.95 & & 0.95 & \\
\hline & & -0.71 & & -0.77 \\
\hline & & -0.73 & & -0.75 \\
\hline & & -0.81 & & -0.86 \\
\hline & & -0.93 & & -0.94 \\
\hline & & -0.93 & 8 & -0.88 \\
\hline & & -0.94 & & -0.89 \\
\hline \multirow{4}{*}{$\begin{array}{l}\text { Intention } \\
\text { int } 1 \\
\text { int } 2 \\
\text { int } 3\end{array}$} & 0.93 & & 0.94 & \\
\hline & & -0.68 & 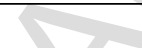 & -0.79 \\
\hline & & -0.74 & 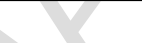 & -0.83 \\
\hline & & -0.81 & 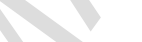 & -0.84 \\
\hline \multirow{4}{*}{$\begin{array}{l}\text { Trust } \\
\text { tru } 1 \\
\text { tru } 2 \\
\text { tru } 3\end{array}$} & 0.93 & 8 & 0.95 & \\
\hline & & -0.87 & 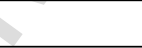 & -0.88 \\
\hline & & -0.86 & & -0.95 \\
\hline & & -0.82 & & -0.88 \\
\hline \multirow{5}{*}{$\begin{array}{l}\text { Habits (country of origin) } \\
\text { hab } 1 \\
\text { hab } 2 \\
\text { hab } 3 \\
\text { hab } 4\end{array}$} & 0.95 & +2 & 0.96 & \\
\hline & & -0.91 & & 0.89 \\
\hline & 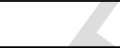 & -0.94 & & 0.94 \\
\hline & +8 & -0.83 & & 0.89 \\
\hline & 0 & -0.74 & & 0.86 \\
\hline \multirow{5}{*}{$\begin{array}{l}\text { Habits (production process) } \\
\text { hab } 5 \\
\text { hab } 6 \\
\text { hab } 7 \\
\text { hab } 8\end{array}$} & 0.98 & & 0.97 & \\
\hline & $\nabla$ & 0.87 & & -0.75 \\
\hline & 8 & 0.90 & & -0.89 \\
\hline & 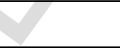 & 0.92 & & -0.91 \\
\hline & & 0.83 & & -0.87 \\
\hline \multirow{5}{*}{$\begin{array}{l}\text { Habits (food assurance) } \\
\text { hab } 9 \\
\text { hab } 10 \\
\text { hab } 11 \\
\text { hab } 12\end{array}$} & 0.97 & & 0.98 & \\
\hline & & -0.87 & & 0.88 \\
\hline & & -0.97 & & 0.87 \\
\hline & & -0.85 & & 0.88 \\
\hline & & -0.85 & & 0.90 \\
\hline \multirow{8}{*}{$\begin{array}{l}\text { Behavioral beliefs } \\
\text { bel } 1 \\
\text { bel } 2 \\
\text { bel } 3 \\
\text { bel } 4 \\
\text { bel } 5\end{array}$} & 0.91 & & 0.90 & \\
\hline & & 0.68 & & 0.54 \\
\hline & & 0.71 & & 0.57 \\
\hline & & 0.42 & & 0.52 \\
\hline & & 0.45 & & 0.50 \\
\hline & & 0.68 & & 0.64 \\
\hline & & 0.75 & & 0.64 \\
\hline & & 0.58 & & 0.52 \\
\hline
\end{tabular}


bel 8

652

bel 9

653

654

655

656

657

658

659

660

661

662

663

664

665

666

667

668

669

670

671

672

673

674

675

676

677

678

679

680

681

682

683

684

685

686

687

688

689

690

691

692

693

694 
Table 4

Correlations between intention and other constructs contained within the minced meat and beef steak TPB- and TPBextended models.

\begin{tabular}{|c|c|c|c|c|c|c|c|c|c|}
\hline Minced meat constructs & 1 & 2 & 3 & 4 & 5 & 6 & 7 & 8 & 9 \\
\hline 1. Intention & - & & & & & & & & \\
\hline 2. Attitude & $0.73 * * *$ & - & & & & & & & \\
\hline 3. Subjective norm & $0.47 * * *$ & $0.42 * * *$ & - & & & & & & \\
\hline 4. $\mathrm{PBC}$ & $0.41 * * *$ & $0.45 * * *$ & $0.18 * *$ & - & & & & & \\
\hline 5. Trust & $0.56 * * *$ & $0.52 * * *$ & $0.22 * * *$ & $0.52 * * *$ & - & & & & \\
\hline $\begin{array}{l}6 . \text { Habits (country of } \\
\text { origin) }\end{array}$ & $0.35 * * *$ & $0.33 * * *$ & 0.10 & 0.11 & $0.24 * * *$ & - & & & \\
\hline $\begin{array}{l}\text { 7. Habits (production } \\
\text { process) }\end{array}$ & $0.25 * * *$ & $0.24 * * *$ & $0.17 * *$ & 0.08 & $0.13 *$ & $0.69 * * *$ & & & \\
\hline 8. Habits (food assurance) & $0.30 * * *$ & $0.22 * * *$ & $0.14 *$ & 0.07 & $0.20 * * *$ & $0.66 * * *$ & $0.72 * * *$ & - & \\
\hline 9. Frequency of purchase & 0.02 & -0.02 & 0.03 & 0.09 & $0.12 *$ & 0.08 & 0.08 & 0.09 & - \\
\hline Beef steak constructs & & & & & & & & & \\
\hline 1. Intention & - & & & & & & & & \\
\hline 2. Attitude & $0.66 * * *$ & - & & & & & & & \\
\hline 3. Subjective norm & $0.48 * * *$ & $0.39 * * *$ & - & & & & & & \\
\hline 4. PBC & $0.41 * * *$ & $0.41 * * *$ & $0.19 * *$ & - & & & & & \\
\hline 5. Trust & $0.46 * * *$ & $0.54 * * *$ & $0.23 * * *$ & $0.48 * * *$ & - & & & & \\
\hline $\begin{array}{l}6 . \text { Habits (country of } \\
\text { origin) }\end{array}$ & $0.33 * * *$ & $0.29 * * *$ & 0.11 & $0.19 * *$ & $0.14 *$ & & & & \\
\hline $\begin{array}{l}\text { 7. Habits (production } \\
\text { process) }\end{array}$ & $0.21 * * *$ & $0.13 *$ & $0.16 * *$ & $0.12 *$ & 0.06 & $0.65 * * *$ & - & & \\
\hline 8. Habits (food assurance) & $0.19 * *$ & $0.14 *$ & $0.16 * *$ & 0.11 & 0.42 & $0.68 * * *$ & $0.77 * * *$ & - & - \\
\hline 9. Frequency of purchase & 0.03 & 0.01 & 0.000 & 0.03 & 0.56 & $0.18 * *$ & 0.18 & 0.11 & - \\
\hline
\end{tabular}

PBC, perceived behavioral control. $p<0.05^{*} ;<0.01^{* *} ;<0.001^{* * *}$; bold numbers highlights significance. 
Table 5

734 Standardized regression coefficients ( $\beta$ ) for both the theory of planned behavior (TPB) constructs and the TPB-extended constructs from regression analysis predicting consumers' intention to buy traceable minced beef and beef steak.

\begin{tabular}{|c|c|c|c|c|}
\hline \multirow[b]{2}{*}{ Independent constructs } & \multicolumn{2}{|l|}{ ТPB } & \multicolumn{2}{|l|}{ TPB-extended } \\
\hline & Minced beef & Beef steak & Minced beef & Beef steak \\
\hline Attitude $^{\mathrm{a}}$ & $0.60 * * *$ & $0.49 * * *$ & $0.48 * * *$ & $0.41 * * *$ \\
\hline Subjective norm ${ }^{\mathrm{a}}$ & $0.20 * * *$ & $0.26 * * *$ & $0.20 * * *$ & $0.27 * * *$ \\
\hline Perceived behavioral control $^{\mathrm{a}}$ & $0.11 * *$ & $0.16 * * *$ & 0.04 & $0.12 *$ \\
\hline Trust $^{\mathrm{a}}$ & & & $0.22 * * *$ & 0.10 \\
\hline Habits (country of origin) ${ }^{\mathrm{a}}$ & & & 0.10 & $0.13 * *$ \\
\hline Habits (production process) ${ }^{\mathrm{a}}$ & & & -0.07 & $0.16 * *$ \\
\hline Habits (food assurance) ${ }^{\mathrm{a}}$ & & & 0.11 & -0.05 \\
\hline Frequency of minced beef or & & & -0.02 & 0.00 \\
\hline steak mince purchase $\mathrm{b}^{\mathrm{b}}$ & & & & \\
\hline$R_{a d j}^{2}$ & 0.57 & 0.51 & 0.62 & 0.53 \\
\hline Model F & $140.07 * * *$ & $105.89 * * *$ & $64.46 * * *$ & $43.15 * *$ \\
\hline$\Delta R^{2}$ & - & - & 0.05 & 0.02 \\
\hline$d f$ & 3,309 & 3,299 & 8,304 & 8,294 \\
\hline
\end{tabular}

${ }^{*} p \leq 0.05 ; * * p<0.01,{ }^{* * *} p<0.001$; bold text highlights significance.

${ }^{a}$ Mean of variable items measured on a 7-point Likert scale; higher scores indicative of stronger (i.e., more positive)

738 levels of the construct.

$739 \mathrm{~b}^{\mathrm{b}} 0=$ less than four times per month, $1=$ once or more weekly. 
Table 6

773 Correlations of behavioral beliefs with attitude and intention for the minced beef and beef steak (italic) sub-groups.

\begin{tabular}{|c|c|c|}
\hline Behavioral beliefs & $\begin{array}{l}\text { Correlation (r) } \\
\text { with attitude }\end{array}$ & $\begin{array}{l}\text { Correlation }(r) \\
\text { with intention }\end{array}$ \\
\hline Traceable minced beef/beef steak will likely be healthier & $0.53 * * * / 0.53 * * *$ & $0.50 * * * / 0.49 * * *$ \\
\hline Traceable minced beef/beef steak will likely be tastier & $0.51 * * * / 0.46 * * *$ & $0.54 * * * / 0.47 * * *$ \\
\hline Traceable minced beef/beef steak will likely be more expensive & $0.25 * * * / 0.18 * *$ & $0.17 * * / 0.11$ \\
\hline Traceable minced beef/beef steak will more likely be of known origin & $0.48 * * * / 0.47 * * *$ & $0.37 * * * / 0.35 * * *$ \\
\hline Traceable minced beef/beef steak will likely be safer & $0.56^{* * *} / 0.56^{* * *}$ & $0.49 * * * / 0.44 * * *$ \\
\hline Traceable minced beef/beef steak will likely be of more satisfying quality & $0.56 * * * / 0.51 * * *$ & $0.54 * * * / 0.51 * * *$ \\
\hline $\begin{array}{l}\text { Traceable minced beef/beef steak will more likely be authentic which } \\
\text { means it has not been tampered with in any way and it is what it says it is }\end{array}$ & $0.55 * * * / 0.60 * * *$ & $0.52 * * * / 0.44 * * *$ \\
\hline $\begin{array}{l}\text { Traceable minced beef/beef steak will likely be more environmentally } \\
\text { friendly }\end{array}$ & $0.49 * * * / 0.54 * * *$ & $0.45 * * * / 0.50 * * *$ \\
\hline $\begin{array}{l}\text { Traceable minced beef/beef steak will likely have higher animal welfare } \\
\text { standards }\end{array}$ & $0.52 * * * / 0.53 * * *$ & $0.44 * * * / 0.43 * * *$ \\
\hline
\end{tabular}


- Respondents reported favorable attitudes and beliefs towards traceable beef.

- Purchase intentions for minced beef and beef steak were similar.

- Attitude is the main driver of behavioral intention.

- In the extended model, trust predicts the intention to buy minced beef.

- In the extended model, habits predict the intention to buy beef steak. 